\title{
9 \\ DESENVOLVIMENTO \\ DO PROJETO DE PESQUISA
}

\subsection{HISTÓRIA DO PROJETO DE MEDIAÇÃO PARA IDOSOS DA PROMOTORIA DE JUSTIÇA CÍVEL DO FORO REGIONAL DE SANTO AMARO, SÃO PAULO}

A partir de um curso teórico de Mediação no Modelo Transformativo realizado pela Escola Superior do Ministério Público, a Promotora de Justiça Cível Dr. ${ }^{a}$ Mônica Lodder de Oliveira dos Santos Pereira e a Procuradora de Justiça Dr.a Isabella Ripoli Martins vislumbraram a possibilidade de serem passíveis de mediação conflitos familiares identificados em Procedimentos Administrativos ${ }^{34}$ instaurados com idosos em situação de risco.

34 Com relação à instauração de Procedimentos Administrativos, o Ato Normativo da Corregedoria Geral do Ministério Público do Estado de São Paulo, n. 857/14 - PGJ - CGMP, de 27 de novembro de 2014, disciplina a atuação do Promotor de Justiça na defesa de idosos em situação de risco, na proteção dos interesses difusos, coletivos e individuais homogêneos de idosos, e na fiscalização das entidades de acolhimento. Dispóe: "Art. 1º Na tutela do idoso, a atuação do Promotor de Justiça deve visar a assegurar os seus direitos e garantias fundamentais, em especial, à liberdade, ao respeito como pessoa humana e como sujeito de direitos civis, políticos, individuais e sociais, à dignidade, à preservação da autonomia, à priorização ao convívio familiar e comunitário e ao acesso da rede de serviços de saúde e de assistência social.Parágrafo único - Caberá ao Promotor de Justiça a iniciativa de ações para prevenir e sancionar qualquer tipo de negligência, discriminação, violência, crueldade, opressão e todos os demais atentados àqueles direitos e garantias. Art. $2^{\circ}$. Em caso de violação ou ameaça de lesão a direito individual indisponível do idoso, caberá ao Promotor de Justiça o exercício de sua defesa, por meio de procedimento administrativo, com finalidade de instrumentalizar as medidas administrativas e judiciais cabíveis". Disponível em <http://www. mpsp. mp. br/portal/page/portal/corregedoria_geral/Atos>.Acesso em: 27 maio 2015. 
Conforme o Estatuto do Idoso (Lei n. 10.741/2003), art. 74, V, compete ao Ministério Público:

Instaurar procedimento administrativo e, para instruí-lo:

a) expedir notificações, colher depoimentos ou esclarecimentos e em caso de não comparecimento injustificado da pessoa notificada requisitar condução coercitiva, inclusive pela Polícia Civil ou Militar;

b) requisitar informações, exames, perícias e documentos de autoridades municipais, estaduais e federais, da administração direta e indireta, bem como promover inspeções e diligências investigatórias;

c) requisitar informações e documentos particulares de instituições privadas.

Chegam à Promotoria de Justiça diversas reclamações com idosos que estão em situação de risco relatadas por vários meios: pelo disque 100; pessoalmente, por familiares, assistentes sociais, terceiros, pelo próprio idoso; por Unidades Básicas de Saúde, Hospitais, Centro de Referência do Idoso, entre outros.

O risco a que o idoso está submetido na maioria das vezes deve-se ao abandono: total ou parcial, material ou moral, que resulta em danos físicos e psicológicos. Geralmente a situação de abandono e/ou falta de cuidados deriva de relaçóes familiares conflituosas.

Exemplos de abandono ou falta de cuidados devidos:

- idosos com saúde debilitada que ficam sozinhos;

- idosos com alta hospitalar que não são buscados pelos familiares;

- inobservância de se levarem os idosos às consultas médicas;

- desprezo frente aos cuidados de medicação prescritos;

- falta de convivência com os filhos.

Nos Procedimentos Administrativos, os conflitos familiares identificados ocorrem quando acontecem dificuldades:

- nos cuidados: nenhum dos filhos se responsabiliza, ou apenas um filho é responsável pelos cuidados e se sobrecarrega nessa função;

- na administração e utilização do benefício do idoso;

- na divisão das despesas para a contratação de um cuidador, para a manutenção da residência do idoso ou para internação;

- na convivência com o idoso.

Com relação à vulnerabilidade, a Constituição Federal Brasileira prescreve o princípio da solidariedade entre as gerações familiares e o princípio do melhor interesse. Nesse sentido, Barletta enfatiza: 
Fazem jus ao mesmo cuidado especial advindo da família os idosos, segundo o princípio do melhor interesse. Observe-se que o cuidado tanto para crianças como para adolescentes quanto o dirigido aos idosos, não se restringe à solidariedade intergeracional no âmbito familiar, mas também à solidariedade que devem provir da sociedade e do Estado em relação aos seus membros mais vulneráveis, em razão da idade reduzida ou avançada (2010, p. 117).

O contexto em que o projeto acontece é cível, as pessoas que fazem parte da representação são chamadas à Promotoria de Justiça Cível para esclarecimentos sobre a situação noticiada do risco.

Antes de o Projeto de Mediação ser acolhido oficialmente pela Promotoria de Justiça Cível de São Paulo, foi realizado um estudo conjunto entre as idealizadoras e três mediadoras voluntárias de como seria possível a mediação em um contexto com mediados vulneráveis. E, a partir de um caso piloto indicado à Mediação, em junho de 2011 foi criado o Projeto como o nome de: Mediação para Idosos da Promotoria de Justiça Cível do Foro Regional de Santo Amaro ${ }^{35}$. Esse nome foi sugerido pela mediadora voluntária Dina Rosa Duarte de Freitas, também idosa, que ressaltou:

muitas vezes a mediação acontecerá para o idoso, em benefício dos seus cuidados, pois pode acontecer de o idoso não estar em condições de saúde para estar presente aos encontros.

Como definição, o Projeto de Mediação para Idosos é a possibilidade de utilização da Mediação para trabalhar a comunicação de idosos em risco com seus familiares, que estejam em conflito, de casos identificados e encaminhados pelos Promotores de Justiça por meio dos Procedimentos Administrativos que acompanham.

Conforme consta na fundamentação do projeto: a Mediação para idosos visa a auxiliar o Ministério Público no apoio ao idoso conforme o artigo $3^{\circ}$ do Estatuto do $\operatorname{Idoso}^{36}$.

\subsection{SUJEITOS DO PROCESSO DE MEDIAÇÃO}

Como sujeitos do processo de mediação estão os mediados e os mediadores. Os mediados convidados, em geral, são os idosos que estão em risco, seus familia-

35 Ver anexo p. 192.

36 Conforme Lei n. 10.741/2003: "É obrigação da família, da comunidade, da sociedade e do Poder Público assegurar ao idoso, com absoluta prioridade, a efetivação do direito à vida, à saúde, à alimentação, à educação, à cultura, ao esporte, ao lazer, ao trabalho, à cidadania, à liberdade, à dignidade, ao respeito e a convivência familiar e comunitária”. 
res, companheiros e cuidadores, que se encontram em conflito e estão relacionados no Procedimento Administrativo.

Como mediadores voluntários no projeto, há uma equipe multidisciplinar com formação no modelo transformativo. Os mediadores possuem diversas profissões de origem (advogado, psicólogo, terapeuta familiar, jornalista, psicopedagoga, linguista, etc.) e todos cumpriram as 160 horas do curso de formação - que são divididas entre as etapas teórica e prática com atendimento supervisionado (de 80 horas cada uma).

Para cada atendimento, atuam conjuntamente: os mediadores de campo e a equipe reflexiva. Os mediadores de campo normalmente têm diferentes profissões de origem e trabalham em duplas (o que é chamado de comediação), atuando em comunicação direta com os mediados. Segundo Parkinson (2016, p. 135) "a comediação interdisciplinar oferece uma gama de conhecimento e experiência que um único mediador não pode proporcionar sozinho". A mesma autora exemplifica como vantagens da comediação:

- Comediadores são mais aptos a conter as necessidades conflitantes e os sentimentos que aparecem na mediação que um único mediador.

- Podem proporcionar equilíbrio físico e psicológico à mediação.

- [Geram um] âmbito de perspectivas mais amplas e diferentes pontos de vista.

- Utilizam uma dinâmica circular, (...) incentivam discussões de debates.

- [Fazem um melhor] monitoramento da prática. A presença de mais de um mediador evita descuidos e omissões.

- Oferecem suporte um para o outro (PARKINSON, 2016, p. 131-133).

Os mediadores de campo são os organizadores do processo, na distribuição da fala, do tempo, da solicitação da fala respeitosa, do agendamento dos próximos encontros. Durante o atendimento, podem ser auxiliados por mediadores reunidos em uma equipe que é chamada de reflexiva. Segundo Grosman e Mandelbaum:

A equipe reflexiva é uma ferramenta utilizada há mais de 20 anos nos trabalhos de terapia familiar. Seu sucesso e sua utilidade são fato, na medida em que oferece a possibilidade de gerar novas reflexōes, por todos os presentes, sobre questôes trazidas à conversa. Para a utilização dessa ferramenta pelo mediador reflexivo, é necessário conhecer suas técnicas, para que as pessoas, que estão participando da mediação, não sintam essas reflexões como ameaças a sua integridade. Ao contrário, a ferramenta é utilizada para que haja, no ambiente de conversa, troca de ideias, ampliando a capacidade de conhecimento, do pensar, do sentir e do fazer (2011, p. 319-320) 
Como visto anteriormente, a equipe reflexiva deriva da terapia familiar; é um sistema de escuta idealizado por Tom Andersen (1991). Os membros da equipe reflexiva desenvolvem "diálogos internos", ou seja, refletem individualmente sobre aquilo que ouviram do campo; quando são convidados a falar, trazem à tona, em voz alta, algumas daquelas reflexões, conversando entre si e não diretamente com os mediados ou com os mediadores. A equipe reflexiva está orientada a compartilhar reflexões e perguntas, as quais por sua vez, podem, ou não, ser respondidas pelos mediados. Segundo esse autor (1991, p. 65-66).

- O sistema entrevistador [mediadores de campo] é visto como um sistema autônomo que define ele próprio o que deve ser conversado e de que maneira isso deve ser feito.

- A equipe reflexiva nunca dá instruções sobre o que o sistema entrevistador deve conversar ou como seus membros devem falar.

- Cada membro da equipe reflexiva escuta silenciosamente a conversa. Os membros não falam entre si, mas cada um se questiona de uma forma inquisitiva.

- Depois de um momento, os membros da equipe apresentam suas ideias se o sistema entrevistador assim o quiser.

- Cada membro da equipe dá sua versão sobre os assuntos problemáticos que foram definidos.

\subsection{DESENVOLVIMENTO DO PROJETO}

Para o desenvolvimento do projeto, foi realizado um estudo prévio pelos mediadores juntamente com as Promotoras de Justiça idealizadoras sobre como eram os Procedimentos Administrativos com idosos em risco, para que se familiarizassem com essa realidade: como chegavam as comunicaçóes dos riscos, quais eram os riscos, quais eram os conflitos identificados, quem poderia ser convidado para a mediação, qual era a situação do idoso no momento do conhecimento do Processo Administrativo, enfim diversas informaçôes que poderiam colaborar para a identificação de quem seriam os mediados ${ }^{37}$ a serem convidados.

Os Promotores de Justiça Cíveis analisam os Procedimentos Administrativos e detectam, entre eles, situações passíveis de serem encaminhadas ao setor de mediação. O Procedimento Administrativo não é suspenso com a mediação; enquanto esta acontece em paralelo, aquele continua com o seu trâmite regular, com

37 São utilizados neste estudo para os participantes da mediação: mediandos - quando em processo de mediação; mediados - quando findo o processo de mediação. 
acompanhamento do Promotor de Justiça responsável, que pode solicitar depoimentos, visitas domiciliares por técnicos, entre diversas outras atuaçóes para o acompanhamento do idoso em risco.

Os mediadores recebem o Procedimento Administrativo encaminhado à Mediação para leitura, para verificarem quem serão os mediandos convidados e se o idoso pode ser convidado. Indicam os nomes dos mediandos e uma data possível para o primeiro encontro.

Os Promotores de Justiça intimam as partes a comparecerem ao primeiro encontro de mediação. Essa intimação aos convidados é para conhecerem a possibilidade da mediação; nos encontros, os mediadores esclarecem que a mediação é um processo voluntário e que nenhum prejuízo resulta da não participação.

Para o desenvolvimento da prática, dois desafios iniciais precisavam ser contemplados: a vulnerabilidade de uma das partes e o princípio do sigilo que faz parte do processo de mediação.

Com relação à vulnerabilidade, já no primeiro encontro os mediandos ficam cientes de: que ali estão pelo e para o idoso; quais são os riscos que foram comunicados no Procedimento Administrativo; que a mediação trabalhará a comunicação familiar inicialmente com relação àqueles riscos; e que os mediadores ali estão como facilitadores do diálogo entre os familiares, não como juízes ou conselheiros.

Quanto ao sigilo, foi feito um estudo cuidadoso da ponderação dos princípios: vida, dignidade humana e sigilo. A mediação é, em regra, um procedimento sigiloso; como, porém, os idosos se encontram em situação periclitante, circunstâncias de risco podem ser comunicadas aos Promotores de Justiça, durante a mediação. Esse tipo de comunicação pode ocorrer se houver:

I - Agravamento da situação de risco em que o idoso se encontra ${ }^{38}$.

II - Comunicação de crime -neste caso, a mediação será encerrada, independentemente da autorização dos mediados, por ser um princípio básico da mediação o encerramento na constatação de crime.

Além dos princípios já mencionados acima (voluntariedade e sigilo), importa considerar que, inobstante as especificidades da mediação realizada com idosos em

38 Os mediandos assinam um Termo de Adesão à Mediação (vide anexo p. 167); nesse documento, autorizam os mediadores a comunicarem o agravamento do risco ao idoso. Essa comunicação é autorizada na Resolução n. 125/2010 do Conselho Nacional de Justiça, no anexo III, referente ao Código de Ética dos Conciliadores e Mediadores Judiciais, no artigo $1^{\circ}$, parágrafo $1^{\circ}$, que trata da confidencialidade: "Confidencialidade - Dever de manter sigilo sobre todas as informações obtidas na sessão, salvo autorização expressa das partes, violação à ordem pública ou às leis vigentes”. 
risco, todos os demais princípios éticos da Mediação e relacionados à função do mediador são respeitados e mantidos no desenvolvimento dos encontros de mediação. Esses podem ser exemplificados pelos princípios norteadores da mediação que Sampaio e Braga Neto (2006, p. 36-38) elencam: imparcialidade, independência do mediador, credibilidade, competência, diligência, acolhimento das emoções dos mediados $^{39}$; boa-fé, respeito, equidade, celeridade, cooperação e informalidade ${ }^{40}$.

Com relação aos principais norteadores da Mediação, Sampaio e Braga Neto destacam (2007, p. 35-40):

- Autonomia da vontade das partes: "o mediador deve assegurar a plena autonomia das partes durante a mediação".

- Imparcialidade: "impõe-se ao mediador o dever de procurar compreender a realidade dos mediados, sem que nenhum preconceito ou valores pessoais interfiram em sua intervenção".

- Independência: "refere-se ao mediador impossibilitado de levar à frente o processo de mediação quando existem ligações anteriores com as partes";

- Confidencialidade: "o mediador deverá manter sigilo sob todas as informaçôes, fatos, relatos, situaçôes, documentos e propostas; (...) deverá garantir que não será testemunha (...)".

- Competência: "ao mediador cabe somente aceitar a tarefa de mediar quando tiver plena convicção de suas qualidades para atender os mediados em seus questionamentos".

- Diligência: "o mediador deverá desenvolver seu trabalho de maneira consciente, prudente e eficaz, assegurando todas as informações aos mediados";

- Acolhimento das emoções: "o mediador deve trabalhar para que, no transcorrer do processo de mediação, os mediados evoluam a fim de reconhecerem a legitimidade das emoções do outro".

O desenvolvimento da prática da mediação tem como objetivo restabelecer ou ampliar a comunicação entre os idosos e seus familiares, o que pode contribuir para a melhora dos cuidados ao idoso e do relacionamento entre os membros da família.

39 Neste estudo, constata-se que há autores que consideram o acolhimento como um princípio da mediação (Sampaio e Braga Neto, 2007); outros o consideram como ferramenta a ser utilizada na mediação, como mais adiante descreve Almeida T. (2014).

40 A Resolução n. 125 do Conselho Nacional de Justiça menciona: Art. 1o São princípios fundamentais que regem a atuação de conciliadores e mediadores judiciais: confidencialidade, decisão informada, competência, imparcialidade, independência e autonomia, respeito à ordem pública e às leis vigentes, empoderamento e validação. 
